\title{
Characteristics of Subjects Who Failed a 120-Minute Spontaneous Breathing Trial
}

\author{
Guopeng Liang MSc, Tingting Liu MSc, Yihua Zeng RN, Yunfeng Shi MSc, Wei Yang MSc, \\ Yunqin Yang MSc, and Yan Kang MD
}

\begin{abstract}
BACKGROUND: The objective of this work was to identify the unique characteristics of patients who experienced success in a 30-min spontaneous breathing trial (SBT) but failed at 120 min. METHODS: Patients who had received mechanical ventilation for $>24 \mathrm{~h}$ were eligible for inclusion in this study. The SBT was performed by $7 \mathrm{~cm} \mathrm{H}_{2} \mathrm{O}$ of pressure support with zero PEEP. After a successful 120-min SBT, weaning from mechanical ventilation was performed. Data were collected at 30 and $120 \mathrm{~min}$ or at the failure of the SBT. All patients who successfully completed a 30-min SBT were enrolled. RESULTS: We enrolled 352 subjects in this study. Of these, 311 subjects $(88.4 \%)$ directly completed a 120-min SBT (success group), and 41 subjects $(11.6 \%)$ passed the test for at least $30 \mathrm{~min}$ but failed before $120 \mathrm{~min}$ (failure group). In data collected before the SBT, presence of chronic cardiopulmonary disease, number of previous SBT attempts before 30-min SBT success, age, and $\mathrm{P}_{\mathrm{aCO}}$ were independently associated with 120 -min SBT failure. A scale was developed that used these 4 variables. The failure rate was low in subjects with $\leq 2$ points $(3 \%)$ but significantly higher in subjects with $>2$ points $(46 \%)$. In data collected at the 30-min SBT, $\mathrm{P}_{\mathrm{aCO}_{2}}$, rapid shallow breathing index, $\Delta \mathrm{P}_{\mathrm{aO}_{2}} / \mathrm{F}_{\mathrm{IO}_{2}}, \Delta$ breathing frequency, and $\Delta \mathrm{pH}$ were independently associated with 120-min SBT failure. These 5 variables were then used to develop another scale to predict SBT success. Similar to the previous score, the failure rate was low in subjects with $\leq 2$ points $(1 \%)$ and significantly higher in subjects with $>2$ points $(55 \%)$. CONCLUSIONS: This study highlights differences between subjects who completed a 120-min SBT and those who succeeded at 30 min but failed by $120 \mathrm{~min}$. In subjects with a score $>\mathbf{2}$ points, reflecting a greater risk of SBT failure, a 120-min SBT may be required. Key words: mechanical ventilation; spontaneous breathing trial; risk factor. [Respir Care 2018;63(4):388-394. (C) 2018 Daedalus Enterprises]
\end{abstract}

\section{Introduction}

Mechanical ventilation is a life-saving tool for critically ill patients, but it is also associated with many complica-

\footnotetext{
Mr Liang, Shi, W Yang, Kang, and Ms Liu and Y Yang are affiliated with the Department of Critical Care Medicine, West China Hospital, Sichuan University, Chengdu, China. Ms Zeng is affiliated with the Department of Respiratory and Critical Care Medicine, West China Hospital, Sichuan University, Chengdu, China.
}

The authors have disclosed no conflicts of interest.

Correspondence: Yan Kang MD, Department of Critical Care Medicine, West China Hospital, Sichuan University, No. 37 Guoxue Road, Chengdu, Sichuan 610041, China. E-mail: Kang_yan_123@yahoo.com or Kang_yan_123@163.com.

DOI: $10.4187 /$ respcare. 05820 tions, such as ventilator-associated pneumonia and ventilator-associated lung injury. ${ }^{1,2}$ Therefore, it is important to wean patients from mechanical ventilation as soon as possible if the respiratory failure that necessitated ventilation has been reversed and the patient is able to sustain spontaneous breathing. However, premature disconnection from mechanical ventilation has been shown to result in a high risk of re-intubation, and delaying extubation also unnecessarily extends the duration of mechanical ventilation and increases the risk of ventilator-associated pneumonia. ${ }^{3,4}$ Therefore, it is necessary to know whether a patient will be able to successfully liberate from mechanical ventilation.

A spontaneous breathing trial (SBT) has been recommended to judge a patient's ability to spontaneously breathe without assistance. ${ }^{5,6}$ Previous studies have reported that outcomes did not differ between subjects who passed a 30or a 120 -min SBT. ${ }^{7,8}$ However, Esteban et $\mathrm{al}^{7}$ observed 
SBT failure rates of $12.2 \%$ in a $30-\min$ SBT and $15.6 \%$ in a 120-min SBT. In addition, Perren et al ${ }^{8}$ reported SBT failure rates of $6.5 \%$ in a $30-\mathrm{min}$ SBT and $11.5 \%$ in a 120-min SBT. These findings indicate that some patients who successfully complete a 30-min SBT may nevertheless fail a 120-min SBT. To the best of our knowledge, no study has yet reported on subjects who experienced success with a 30-min SBT but failure with a 120-min SBT. Thus, we aimed to identify the clinical characteristics of subjects who passed a 30-min SBT but went on to fail a 120-min SBT.

\section{See the Related Editorial on Page 493}

\section{Methods}

This study was prospectively performed in the ICU of a teaching hospital between March 2016 and April 2017, and the investigational review board approved the study protocol. Before enrollment, all patients or next of kin provided informed consent. All patients who had been receiving mechanical ventilation for $>24 \mathrm{~h}$ were potential cases for this study. If they passed at least a 30-min SBT, we enrolled them in this study. Patients with a tracheotomy or $<18$ y of age were excluded from participation.

Subjects were managed according to the guidelines recommended by the Society of Critical Care Medicine of China. ${ }^{6}$ Orotracheal intubation was the first choice to build an artificial airway. However, in patients with difficult orotracheal intubation, nasotracheal intubation was instead performed with guidance from a bronchofibroscope. The cuff pressure of the endotracheal tube was maintained at $25-30 \mathrm{~cm} \mathrm{H}_{2} \mathrm{O}$ to prevent mucosal injury, and it was measured every $8 \mathrm{~h}$. Active humidification was performed in all subjects, and the temperature was maintained at $37^{\circ} \mathrm{C}$. The circuit of the ventilator was changed every $7 \mathrm{~d}$. However, if the circuit was visibly soiled or if it malfunctioned, it was changed immediately. Tidal volume was maintained at $8 \mathrm{~mL} / \mathrm{kg}$ of predicted body weight in subjects without ARDS and at $6 \mathrm{~mL} / \mathrm{kg}$ of predicted body weight in subjects with ARDS. Sedation was performed to reduce the work of breathing or reach optimal patient-ventilator interaction. Typically, the sedation was titrated to maintain a breathing frequency of $<30$ breaths/min and a Richmond Agitation-Sedation Scale of +1 to -2 .

We used pressure support ventilation to wean subjects from mechanical ventilation. Every morning, the respiratory therapists screened the subjects to identify those who were eligible for an SBT. The criteria for SBT were as follows: sufficient improvement of the underlying causes that required mechanical ventilation, $\mathrm{P}_{\mathrm{aO}_{2}} / \mathrm{F}_{\mathrm{IO}_{2}}>150-200$ $\mathrm{mm} \mathrm{Hg}$, PEEP $<5-8 \mathrm{~cm} \mathrm{H}_{2} \mathrm{O}, \mathrm{F}_{\mathrm{IO}_{2}} \leq 0.5$, stable hemodynamics, body temperature $<38.5^{\circ} \mathrm{C}$, and subject wake-

\section{QUICK LOOK}

\section{Current knowledge}

The recommended duration of a spontaneous breathing trial (SBT) has been between 30 and 120 min. However, some patients have a successful 30-min SBT but fail at $120 \mathrm{~min}$. The clinical characteristics differentiating these groups are unclear.

\section{What this paper contributes to our knowledge}

This study, using a pressure support level of $7 \mathrm{~cm} \mathrm{H}_{2} \mathrm{O}$, found that the presence of chronic cardiopulmonary disease, SBT attempts before $30-\mathrm{min}$ SBT success, age, $\mathrm{P}_{\mathrm{aCO}_{2}}$, rapid shallow breathing index, $\Delta \mathrm{P}_{\mathrm{aO}_{2}} / \mathrm{F}_{\mathrm{IO}_{2}}$ (subtracting the value collected at the beginning of the SBT from the value collected at $30 \mathrm{~min}$; T30-T0), $\Delta$ breathing frequency $(\mathrm{T} 30-\mathrm{T} 0)$, and $\Delta \mathrm{pH}(\mathrm{T} 30-\mathrm{T} 0)$ were predictors of 30-min SBT success but 120-min failure. The failure rate increased with an increased risk score. In patients with risk score $>2$ points, 120 -min SBT may be required.

fulness (without continuous sedation). The 120-min SBT was performed with low-pressure support $\left(7 \mathrm{~cm} \mathrm{H}_{2} \mathrm{O}\right)$ with no PEEP and the same level of $\mathrm{F}_{\mathrm{IO}_{2}}$ used during mechanical ventilation. Failure of an SBT was defined if the following occurred: breathing frequency $>35$ breaths $/ \mathrm{min}$, rapid shallow breathing index (f/tidal volume) $>105$, heart rate $>140$ beats $/ \mathrm{min}$, systolic blood pressure $>180$ or $<90 \mathrm{~mm} \mathrm{Hg}, \mathrm{P}_{\mathrm{aO}_{2}}<60 \mathrm{~mm} \mathrm{Hg}$ or $\mathrm{P}_{\mathrm{aO}_{2}} / \mathrm{F}_{\mathrm{IO}_{2}}<150 \mathrm{~mm} \mathrm{Hg}$, presence of acute hypoventilation and an increase of $\mathrm{P}_{\mathrm{aCO}}$ by at least $10 \mathrm{~mm} \mathrm{Hg}$, and presence of labored breathing resembling that seen during vigorous activity (eg, contraction of accessory muscles or a paradoxical abdominal breathing pattern). If the SBT failed, mechanical ventilation was reinstituted according to previous parameters, and weaning screening was repeated the next day. If the 120min SBT was successfully completed, the endotracheal tube was removed.

Vital signs and arterial blood gas tests were collected at initiation, after $30 \mathrm{~min}$ of SBT, and at failure or after $120 \mathrm{~min}$ of SBT. Subjects who experienced success for at least $30 \mathrm{~min}$ but failed before reaching $120 \mathrm{~min}$ were placed into the failure group, and those who directly passed the 120-min SBT were placed into the success group.

\section{Statistical Analysis}

Data were reported as mean values and SD, median values and interquartile ranges, or numbers and percent- 
Table 1. Demographics at enrollment

\begin{tabular}{|c|c|c|c|}
\hline Characteristic & Failure $(n=41)$ & Success $(n=311)$ & $P$ \\
\hline Age, mean \pm SD y & $74 \pm 11$ & $63 \pm 15$ & $<.001$ \\
\hline Female/male, $n$ & $21 / 20$ & $114 / 197$ & .09 \\
\hline \multicolumn{4}{|l|}{ Reason for mechanical ventilation, $n(\%)$} \\
\hline Pneumonia & $12(29)$ & $81(26)$ & .71 \\
\hline Trauma & $4(10)$ & $68(22)$ & .10 \\
\hline COPD exacerbation & $14(34)$ & $23(7)$ & $<.001$ \\
\hline Asthma & $0(0)$ & $17(5)$ & .24 \\
\hline Postoperative respiratory failure & $3(7)$ & $45(14)$ & .33 \\
\hline Sepsis & $2(5)$ & $35(11)$ & .28 \\
\hline Cardiogenic pulmonary edema & $1(2)$ & $18(6)$ & .71 \\
\hline Cardiac arrest & $2(5)$ & $9(3)$ & .37 \\
\hline Others & $3(7)$ & $15(5)$ & .22 \\
\hline \multicolumn{4}{|l|}{ Underlying disease, $n(\%)$} \\
\hline Chronic lung disease & $17(41)$ & $33(10.6)$ & $<.001$ \\
\hline Chronic heart disease & $7(17)$ & $16(5.1)$ & .01 \\
\hline Both chronic lung and heart disease & $5(12)$ & $15(4.8)$ & .069 \\
\hline Presence of chronic lung or heart disease & $29(71)$ & $64(21)$ & $<.001$ \\
\hline Days of mechanical ventilation before the first SBT attempt, mean $\pm \mathrm{SD}$ & $5.1 \pm 1.8$ & $4.4 \pm 1.8$ & .02 \\
\hline SBT attempts before 30 -min SBT success, mean \pm SD & $1.1 \pm 1.1$ & $0.1 \pm 0.4$ & $<.001$ \\
\hline SBT attempts before 30-min SBT success, median (IQR) & $1(0-2)$ & $0(0-0)$ & \\
\hline Time from initiation of SBT to failure, mean \pm SD min & $94 \pm 24$ & & NA \\
\hline \multicolumn{4}{|l|}{$\begin{array}{l}\mathrm{SBT}=\text { spontaneous breathing trial } \\
\mathrm{IQR}=\text { interquartile range } \\
\mathrm{NA}=\text { not applicable }\end{array}$} \\
\hline
\end{tabular}

ages when appropriate. The differences between groups were analyzed using statistical software (SPSS 20.0, SPSS, Chicago, Illinois). For continuous variables, the difference between 30 min of SBT and initiation of SBT (T30-T0) was calculated by subtracting the value collected at the beginning of the SBT from the value collected at $30 \mathrm{~min}$. To identify independent risk factors associated with 120-min SBT failure, variables with $P<.20$ in the univariate analysis were entered into a multivariable logistic regression model. A score was developed according to the weight ( $\beta$ regression coefficient) of each variable. ${ }^{9} P<.05$ was considered to indicate a significant difference.

\section{Results}

A total of 352 subjects successfully completed a 30-min SBT and were enrolled in this study. Of these, 41 subjects $(11.6 \%)$ had failed by $120 \mathrm{~min}$ (failure group), and 311 subjects successfully completed the 120-min SBT (success group). Compared with the success group, subjects in the failure group were older, had longer duration of mechanical ventilation before the first SBT attempt, and had made more SBT attempts before successfully completing a 30min SBT (Table 1).
Just before the SBT, subjects in the failure group had a higher heart rate and higher $\mathrm{P}_{\mathrm{aCO}}$ than those in the success group (Table 2). After 30 min of the SBT, they also had a higher heart rate, a higher breathing frequency, a higher rapid shallow breathing index, and higher $\mathrm{P}_{\mathrm{aCO}}$. In addition, greater changes were seen in vital signs and arterial blood gas tests between the beginning of the SBT and 30 min.

Before performance of an SBT, the presence of chronic cardiopulmonary disease, the number of SBT attempts before 30-min SBT success, age, and $\mathrm{P}_{\mathrm{aCO}}$ were independently associated with 120-min SBT failure (Table 3). The cutoff values, sensitivity, and specificity are summarized in Table 4. Points were assigned to each variable according to the $\beta$ regression coefficient to create a risk scale. The failure rates were $2,7,0,33,36$, and $100 \%$ in subjects with $0,1,2,3,4$, and $\geq 5$ points, respectively (Fig. 1 ). In data collected at $30 \mathrm{~min}, \mathrm{P}_{\mathrm{aCO}}$, rapid shallow breathing index, $\Delta \mathrm{P}_{\mathrm{aO}_{2}} / \mathrm{F}_{\mathrm{IO}_{2}}$ (T30-T0), $\Delta$ breathing frequency (T30$\mathrm{T} 0$ ), and $\Delta \mathrm{pH}$ (T30-T0) were independently associated with 120-min SBT failure. Finally, another scale was developed using the weight of each variable. Failure rates were $0,0,7,16,33,75$, and $100 \%$ in subjects with $0,1,2$, $3,4,5$, and $\geq 6$ points, respectively. The power of this scale to predict 120 -min SBT failure is summarized in 
Table 2. Comparisons Between Groups

\begin{tabular}{|c|c|c|c|}
\hline Characteristics & Failure $(n=41)$ & Success $(n=311)$ & $P$ \\
\hline \multicolumn{4}{|l|}{ Before SBT } \\
\hline Breathing frequency, breaths/min & $19 \pm 3$ & $20 \pm 4$ & .07 \\
\hline Rapid shallow breathing index & $53 \pm 11$ & $50 \pm 17$ & .28 \\
\hline Heart rate, beats/min & $85 \pm 10$ & $80 \pm 13$ & .02 \\
\hline Systolic blood pressure, $\mathrm{mm} \mathrm{Hg}$ & $121 \pm 16$ & $123 \pm 17$ & .46 \\
\hline Diastolic blood pressure, $\mathrm{mm} \mathrm{Hg}$ & $70 \pm 8$ & $72 \pm 8$ & .13 \\
\hline $\mathrm{pH}$ & $7.44 \pm 0.04$ & $7.44 \pm 0.04$ & .38 \\
\hline $\mathrm{P}_{\mathrm{aCO}_{2}} \mathrm{~mm} \mathrm{Hg}$ & $47 \pm 9$ & $40 \pm 6$ & $<.001$ \\
\hline $\mathrm{P}_{\mathrm{aO}_{2}} / \mathrm{F}_{\mathrm{IO}_{2}}$ & $248 \pm 53$ & $235 \pm 59$ & .18 \\
\hline \multicolumn{4}{|l|}{ At $30 \mathrm{~min}$ of $\mathrm{SBT}$} \\
\hline Breathing frequency, breaths/min & $26 \pm 4$ & $22 \pm 4$ & $<.001$ \\
\hline Rapid shallow breathing index & $77 \pm 15$ & $61 \pm 16$ & $<.001$ \\
\hline Heart rate, beats/min & $96 \pm 12$ & $87 \pm 12$ & $<.001$ \\
\hline Systolic blood pressure, $\mathrm{mm} \mathrm{Hg}$ & $127 \pm 16$ & $123 \pm 17$ & .16 \\
\hline Diastolic blood pressure, $\mathrm{mm} \mathrm{Hg}$ & $72 \pm 11$ & $72 \pm 8$ & .84 \\
\hline $\mathrm{pH}$ & $7.39 \pm 0.05$ & $7.44 \pm 0.05$ & $<.001$ \\
\hline $\mathrm{P}_{\mathrm{aCO}_{2}} \mathrm{~mm} \mathrm{Hg}$ & $50 \pm 9$ & $41 \pm 6$ & $<.001$ \\
\hline $\mathrm{P}_{\mathrm{aO}_{2}} / \mathrm{F}_{\mathrm{IO}_{2}}$ & $241 \pm 53$ & $237 \pm 61$ & .64 \\
\hline$\Delta$ Breathing frequency $(\mathrm{T} 30-\mathrm{T} 0)$, breaths/min & $7 \pm 4$ & $2 \pm 1$ & $<.001$ \\
\hline$\Delta$ Rapid shallow breathing index (T30-T0) & $25 \pm 17$ & $12 \pm 3$ & $<.001$ \\
\hline$\Delta$ Heart rate $(\mathrm{T} 30-\mathrm{T} 0)$, beats $/ \mathrm{min}$ & $11 \pm 11$ & $7 \pm 3$ & $<.001$ \\
\hline$\Delta \mathrm{pH}(\mathrm{T} 30-\mathrm{T} 0)$ & $-0.05 \pm 0.06$ & $0.00 \pm 0.04$ & $<.001$ \\
\hline$\Delta \mathrm{P}_{\mathrm{aCO}_{2}}(\mathrm{~T} 30-\mathrm{T} 0)$ & $3 \pm 5$ & $1 \pm 4$ & .005 \\
\hline$\Delta \mathrm{P}_{\mathrm{aO}_{2}} / \mathrm{F}_{\mathrm{IO}_{2}}(\mathrm{~T} 30-\mathrm{T} 0)$ & $-7 \pm 36$ & $1 \pm 13$ & .004 \\
\hline \multicolumn{4}{|l|}{ At $120 \mathrm{~min}$ of $\mathrm{SBT}^{*}$} \\
\hline Breathing frequency, breaths/min & $35 \pm 5$ & $22 \pm 5$ & $<.001$ \\
\hline Rapid shallow breathing index & $113 \pm 23$ & $67 \pm 16$ & $<.001$ \\
\hline Heart rate, beats/min & $128 \pm 19$ & $87 \pm 13$ & $<.001$ \\
\hline Systolic blood pressure, $\mathrm{mm} \mathrm{Hg}$ & $140 \pm 20$ & $125 \pm 17$ & $<.001$ \\
\hline Diastolic blood pressure, $\mathrm{mm} \mathrm{Hg}$ & $73 \pm 7$ & $72 \pm 9$ & .35 \\
\hline $\mathrm{pH}$ & $7.35 \pm 0.07$ & $7.43 \pm 0.05$ & $<.001$ \\
\hline $\mathrm{P}_{\mathrm{aCO}_{2}}, \mathrm{~mm} \mathrm{Hg}$ & $56 \pm 13$ & $41 \pm 7$ & $<.001$ \\
\hline $\mathrm{P}_{\mathrm{aO}_{2}} / \mathrm{F}_{\mathrm{IO}_{2}}$ & $195 \pm 68$ & $243 \pm 61$ & $<.001$ \\
\hline \multicolumn{4}{|c|}{$\begin{array}{l}\text { Results are mean } \pm \text { SD. } \\
\text { * In the failure group, } 25 \text { subjects required immediate reinstitution of mechanical ventilation at }<120 \mathrm{~min} \text {, and the data were collected at spontaneous breathing trial failure. } \\
\text { SBT }=\text { spontaneous breathing trial } \\
\text { T30-T0 = difference between } 30 \mathrm{~min} \text { and the initiation of spontaneous breathing trial }\end{array}$} \\
\hline
\end{tabular}

Figure 2. A decision tree was developed in Figure 3 to show whether to prolong the SBT to $120 \mathrm{~min}$.

\section{Discussion}

The current study observed an incidence of 30-min SBT success paired with 120 -min failure of $11.6 \%$. Before SBT, the presence of chronic cardiopulmonary disease, number of SBT attempts before 30-min SBT success, age, and $\mathrm{P}_{\mathrm{aCO}_{2}}$ were independently associated with 30-min SBT success +120 -min SBT failure. In addition, $\mathrm{P}_{\mathrm{aCO}_{2}}$, rapid shallow breathing index, $\Delta \mathrm{P}_{\mathrm{aO}_{2}} / \mathrm{F}_{\mathrm{IO}_{2}}$ (T30-T0), $\Delta$ breathing frequency (T30-T0), and $\Delta \mathrm{pH}$ (T30-T0) after $30 \mathrm{~min}$ of SBT were independently associated with 30-min SBT suc- cess +120 -min failure. Subjects with a higher score that incorporated these risk factors had a higher risk of 120min SBT failure.

Several guidelines have recommended an SBT to assess readiness for ventilator weaning. 5,6 A duration of between 30 and $120 \mathrm{~min}$ has also been recommended (ie, the SBT should last at least $30 \mathrm{~min}$ but no more than $120 \mathrm{~min}$ ). However, 2 studies reported that the SBT failure rate was higher in subjects who received a 120-min SBT than in those who received only a 30-min SBT. ${ }^{7,8}$ This indicates that some subjects passed a 30-min SBT but encountered failure by $120 \mathrm{~min}$. To the best of our knowledge, no study has yet reported the characteristics of these patients. Our study found that, in subjects with a risk score $\leq 2$ points, a 
30-min SBT may be sufficient. However, in subjects with a risk score $>2$ points, a 120-min SBT may be required.

In a previous study reported by Thille et al, ${ }^{10}$ subjects with advanced age and chronic cardiopulmonary disease were more likely to experience extubation failure. In their study, the SBT lasted only $60 \mathrm{~min}$, indicating that a 60 min SBT may be inadequate to assess the ability of patients with advanced age or chronic cardiopulmonary disease to breathe unassisted. In another study focused on the elderly, the SBT failure rate increased from 20.3 to $35.8 \%$ if the duration of SBT was lengthened from 2 to $8 \mathrm{~h}$; however, the extubation failure rate decreased from 48.4 to $7.5 \% .{ }^{11}$ This study further confirmed that a lengthened

Table 3. Multivariable Logistic Regression Analysis Identifying Independent Risk Factors for 30-Minute SBT Success but 120-Minute Failure

\begin{tabular}{|c|c|c|}
\hline Characteristics & OR $(95 \% \mathrm{CI})$ & $P$ \\
\hline \multicolumn{3}{|l|}{ Before SBT } \\
\hline Presence of chronic lung or heart disease & $3.21(1.22-8.42)$ & .02 \\
\hline SBT attempts before 30 -min SBT success & $5.42(3.04-9.67)$ & $<.001$ \\
\hline Age, y & $1.08(1.03-1.14)$ & .002 \\
\hline $\mathrm{P}_{\mathrm{aCO}_{2}} \mathrm{~mm} \mathrm{Hg}$ & $1.07(1.02-1.14)$ & .01 \\
\hline \multicolumn{3}{|l|}{ At $30 \mathrm{~min}$ of SBT } \\
\hline $\mathrm{P}_{\mathrm{aCO}_{2}}, \mathrm{~mm} \mathrm{Hg}$ & $1.14(1.07-1.22)$ & $<.001$ \\
\hline Rapid shallow breathing index & $1.06(1.02-1.09)$ & $<.001$ \\
\hline$\Delta \mathrm{P}_{\mathrm{aO}_{2}} / \mathrm{F}_{\mathrm{IO}_{2}}(\mathrm{~T} 30-\mathrm{T} 0)$ & $0.96(0.93-0.99)$ & .03 \\
\hline$\Delta$ Breathing frequency $(\mathrm{T} 30-\mathrm{T} 0)$ & $1.65(1.39-1.95)$ & $<.001$ \\
\hline$\Delta \mathrm{pH}(\mathrm{T} 30-\mathrm{T} 0)$ & $0.00(0.00-0.36)$ & .033 \\
\hline
\end{tabular}

$\overline{\text { The variables with } P}<0.20$ in univariate analysis were entered into the multivariable logistic regression model.

$\mathrm{OR}=$ odds ratio

$\mathrm{SBT}=$ spontaneous breathing trial

$\mathrm{T} 30-\mathrm{T} 0=$ difference between $30 \mathrm{~min}$ and the initiation of spontaneous breathing trial
SBT may be required in older patients. In our study, the mean time between initiation and SBT failure was $94 \mathrm{~min}$ in subjects who experienced a 30-min SBT success paired with 120-min failure. Advanced age and the presence of chronic cardiopulmonary disease were each risk factors for 30-min SBT success + 120-min SBT failure. Thus, a longer duration of SBT may be more appropriate in patients with advanced age or presence of chronic cardiopulmonary disease.

In our study, we also found that subjects who had already made one or more SBT attempts before this study were more likely to experience 30 -min SBT success but 120-min failure. These subjects were classified as those with difficult or prolonged weaning based on the consensus of the European Respiratory Society, the American Thoracic Society, and the European Society of Intensive Care Medicine. ${ }^{12}$ After a 30-120-min SBT, subjects with this classification more often experience a higher rate of extubation failure than subjects who have undergone simple weaning. ${ }^{13}$ This may indicate that a $30-120$-min SBT may not fully identify the ability of difficult or prolongedweaning patients to spontaneously breathe. A longer SBT may be required in these patients.

The rapid shallow breathing index is commonly measured during SBT to predict successful weaning. However, a previous study reported that the rapid shallow breathing index increased significantly after $30 \mathrm{~min}$ of the SBT and increased further after $60 \mathrm{~min}$ in subjects with extubation failure but did not increase in subjects with extubation success. ${ }^{14}$ In this study, the rapid shallow breathing index was increased but still within an acceptable range after a 30-min SBT. However, when the SBT lasted $60 \mathrm{~min}$, the rapid shal-

Table 4. Sensitivity, Specificity, and Points Assigned to Independent Risk Factors

\begin{tabular}{|c|c|c|c|c|c|c|c|}
\hline Characteristics & Area Under the Curve $(95 \% \mathrm{CI})$ & Cutoff Value & $\mathrm{SE}, \%$ & $\mathrm{SP}, \%$ & OR $(95 \% \mathrm{CI})$ & $\beta$ & Points \\
\hline \multicolumn{8}{|l|}{ Before SBT } \\
\hline Presence of chronic lung or heart disease & $0.75(0.70-0.80)$ & Yes & 70.73 & 79.42 & $9.3(4.5-19.3)$ & 1.01 & 1 \\
\hline SBT attempts before 30 -min SBT success & $0.78(0.74-0.82)$ & $\geq 1$ & 31.71 & 96.78 & $19.8(9.3-42.2)$ & 2.90 & 3 \\
\hline Age, y & $0.74(0.69-0.79)$ & $\geq 75$ & 58.54 & 87.78 & $10.1(5.0-20.6)$ & 1.10 & 1 \\
\hline $\mathrm{P}_{\mathrm{aCO}_{2}} \mathrm{~mm} \mathrm{Hg}$ & $0.75(0.70-0.80)$ & $\geq 48$ & 48.78 & 93.25 & $13.8(6.5-29.2)$ & 2.22 & 2 \\
\hline \multicolumn{8}{|l|}{ At $30 \mathrm{~min}$ of SBT } \\
\hline $\mathrm{P}_{\mathrm{aCO}_{2}}, \mathrm{~mm} \mathrm{Hg}$ & $0.79(0.74-0.83)$ & $\geq 50$ & 53.66 & 92.93 & $15.2(7.2-32.2)$ & 2.63 & 2 \\
\hline Rapid shallow breathing index & $0.76(0.72-0.81)$ & $\geq 69$ & 68.29 & 70.10 & $5.0(2.5-10.2)$ & 1.99 & 1 \\
\hline$\Delta \mathrm{P}_{\mathrm{aO}_{2}} / \mathrm{F}_{\mathrm{IO}_{2}}(\mathrm{~T} 30-\mathrm{T} 0)$ & $0.57(0.52-0.63)$ & $\leq-13$ & 34.15 & 94.53 & $8.8(3.7-20.7)$ & 3.17 & 2 \\
\hline$\Delta$ Breathing frequency $(\mathrm{T} 30-\mathrm{T} 0)$ & $0.82(0.78-0.86)$ & $\geq 3$ & 80.49 & 96.46 & $113(42-299)$ & 5.04 & 3 \\
\hline$\Delta \mathrm{pH}(\mathrm{T} 30-\mathrm{T} 0)$ & $0.77(0.73-0.82)$ & $\leq-0.02$ & 78.05 & 66.88 & $6.0(3.0-12.2)$ & 1.70 & 1 \\
\hline \multicolumn{8}{|c|}{$\begin{array}{l}\text { One point was assigned in the variable with lowest weight ( } \beta \text { regression coefficient). Then weight in other variables was divided by the lowest weight. The result was rounded to the nearest whole } \\
\text { number as the assigned points. } \\
\text { SE }=\text { sensitivity } \\
\text { SP }=\text { specificity } \\
\text { OR }=\text { odds ratio } \\
\text { SBT }=\text { spontaneous breathing trial }\end{array}$} \\
\hline
\end{tabular}



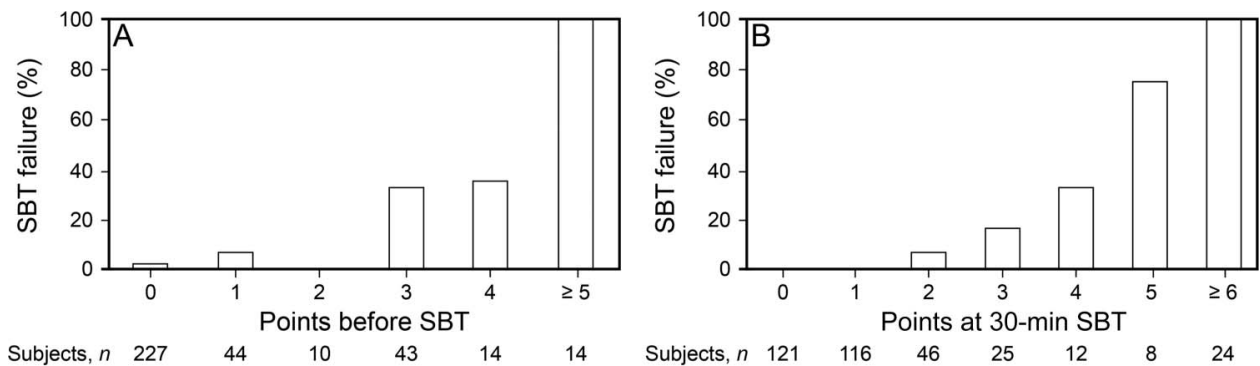

Fig. 1. 120-min spontaneous breathing trial failure rate in subjects with different points on the risk scale. SBT = spontaneous breathing trial.
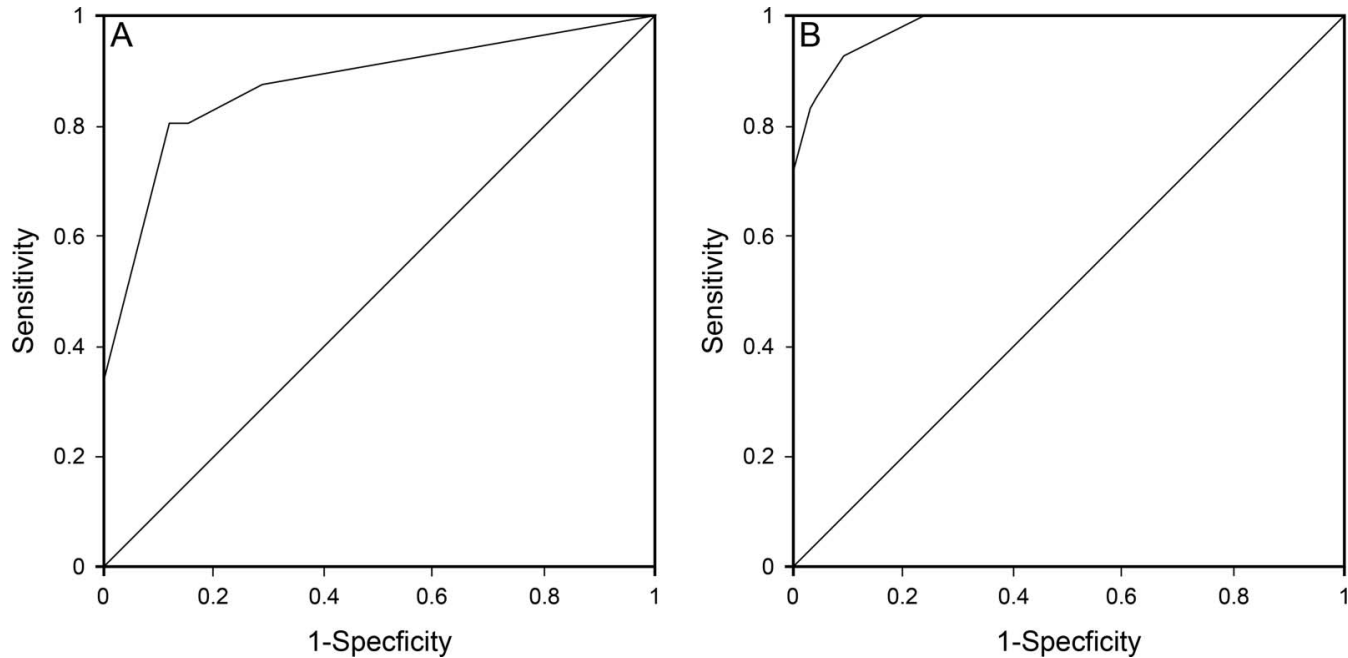

Fig. 2. Power of risk scores to identify subjects who would experience 120-min spontaneous breathing trial (SBT) failure. A: Score developed before SBT, area under the curve $=0.88(95 \% \mathrm{Cl} 0.81-0.95)$. B: Score developed at $30 \mathrm{~min}$ of SBT, area under the curve $=0.98(95 \% \mathrm{Cl}$ $0.96-0.99)$.
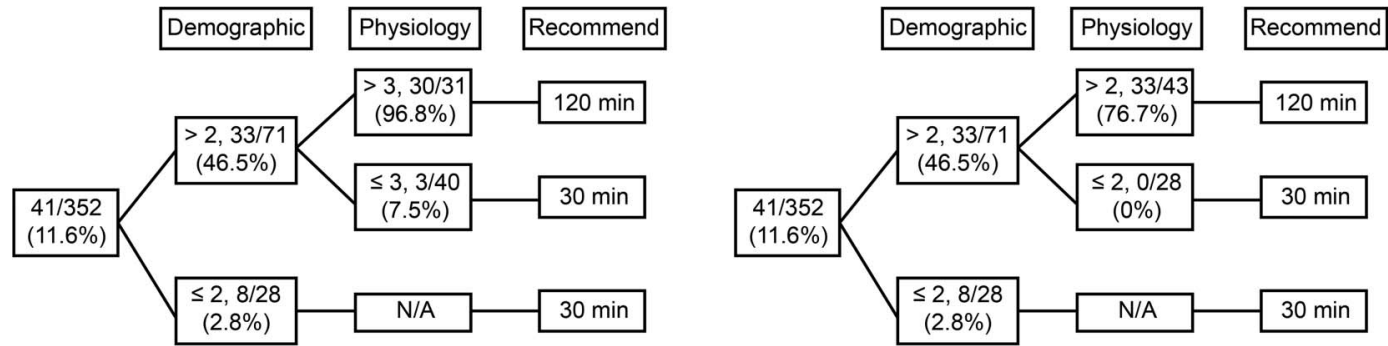

Fig. 3. The decision tree to determine whether to prolong the SBT to $120 \mathrm{~min}$. Different SBT failure rates in subjects with different points were descried in 2 models. The 2 models provide references for clinical practitioners to decide whether or not to prolong the SBT to 120 min.

low breathing index exceeded accepted ranges. This serves as yet another indicator that a 30-min SBT may overestimate spontaneous breathing ability. In our study, we found that subjects with a rapid shallow breathing index $>69$ at $30 \mathrm{~min}$ of SBT were more likely to experience 30-min SBT success but proceed to failure at $120 \mathrm{~min}$. In these patients, a longer duration of SBT may be more reasonable.

Our study was limited by the methodology. The SBT was applied via low-pressure support. However, a lowpressure support may overestimate the ability of the body to spontaneously breathe compared with a T-piece. ${ }^{15}$ Also, subjects with a T-piece were more likely to experience
SBT failure than subjects with a low-pressure support. ${ }^{16}$ Therefore, the use of low-pressure support may mask early SBT failure. This may partly explain why $11.6 \%$ of subjects experienced at least $30 \mathrm{~min}$ of SBT success but failed by $120 \mathrm{~min}$ in our study. However, SBT also can be performed using a continuous positive airway pressure device or a T-piece. Because these 2 methods were not involved in our study, this issue requires further exploration. In addition, the decision tree was developed in accordance with the cut-off value measured at the beginning and at $30 \mathrm{~min}$ of SBT. However, the power of the decision tree needs to be duplicated in multi-center trials. 


\section{Conclusions}

A 30-min SBT performed with $7 \mathrm{~cm} \mathrm{H}_{2} \mathrm{O}$ of pressure support may overestimate the ability to spontaneously breathe. In subjects with a risk score $\leq 2$ points, the 30 min SBT was sufficient. However, in those with a risk score $>2$ points, a 120-min SBT may be required.

\section{REFERENCES}

1. Rello J, Ollendorf DA, Oster G, Vera-Llonch M, Bellm L, Redman $\mathrm{R}$, et al. Epidemiology and outcomes of ventilator-associated pneumonia in a large US database. Chest 2002;122(6):2115-2121.

2. Gajic O, Dara SI, Mendez JL, Adesanya AO, Festic E, Caples SM, et al. Ventilator-associated lung injury in patients without acute lung injury at the onset of mechanical ventilation. Crit Care Med 2004; 32(9):1817-1824.

3. Torres A, Gatell JM, Aznar E, el-Ebiary M, Puig de la Bellacasa J, González J, et al. Re-intubation increases the risk of nosocomial pneumonia in patients needing mechanical ventilation. Am J Respir Crit Care Med 1995;152(1):137-141.

4. Coplin WM, Pierson DJ, Cooley KD, Newell DW, Rubenfeld GD. Implications of extubation delay in brain-injured patients meeting standard weaning criteria. Am J Respir Crit Care Med 2000;161(5): 1530-1536.

5. MacIntyre NR, Cook DJ, Ely EW Jr, Epstein SK, Fink JB, Heffner $\mathrm{JE}$, et al. Evidence-based guidelines for weaning and discontinuing ventilatory support: a collective task force facilitated by the American College of Chest Physicians; the American Association for Respiratory Care; and the American College of Critical Care Medicine. Chest 2001;120(6 Suppl):375S-395S.

6. Society of Critical Care Medicine, Chinese Medical Association. [Practical guidelines for mechanical ventilation (2006)]. Zhongguo Wei Zhong Bing Ji Jiu Yi Xue 2007;19(2):65-72.
7. Esteban A, Alía I, Tobin MJ, Gil A, Gordo F, Vallverdú I, et al. Effect of spontaneous breathing trial duration on outcome of attempts to discontinue mechanical ventilation. Spanish Lung Failure Collaborative Group. Am J Respir Crit Care Med 1999;159(2):512-518.

8. Perren A, Domenighetti G, Mauri S, Genini F, Vizzardi N. Protocoldirected weaning from mechanical ventilation: clinical outcome in patients randomized for a 30 -min or 120 -min trial with pressure support ventilation. Intensive Care Med 2002;28(8):1058-1063.

9. Brueckmann B, Villa-Uribe JL, Bateman BT, Grosse-Sundrup M, Hess DR, Schlett CL, Eikermann M. Development and validation of a score for prediction of postoperative respiratory complications. Anesthesiology 2013;118(6):1276-1285.

10. Thille AW, Harrois A, Schortgen F, Brun-Buisson C, Brochard L. Outcomes of extubation failure in medical intensive care unit patients. Crit Care Med 2011;39(12):2612-2618.

11. Su KC, Tsai CC, Chou KT, Lu CC, Liu YY, Chen CS, et al. Spontaneous breathing trial needs to be prolonged in critically ill and older patients requiring mechanical ventilation. J Crit Care 2012; 27(3):324.e1-7.

12. Funk GC, Anders S, Breyer MK, Burghuber OC, Edelmann G, Heindl $\mathrm{W}$, et al. Incidence and outcome of weaning from mechanical ventilation according to new categories. Eur Respir J 2010;35(1):88-94.

13. Sellares J, Ferrer M, Cano E, Loureiro H, Valencia M, Torres A. Predictors of prolonged weaning and survival during ventilator weaning in a respiratory ICU. Intensive Care Med 2011;37(5):775-784.

14. Liu Y, Wei LQ, Li GQ, Lv FY, Wang H, Zhang YH, Cao WL. A decision-tree model for predicting extubation outcome in elderly patients after a successful spontaneous breathing trial. Anesth Analg 2010;111(5):1211-1218.

15. Sklar MC, Burns K, Rittayamai N, Lanys A, Rauseo M, Chen L, et al. Effort to breathe with various spontaneous breathing trial techniques: a physiological meta-analysis. Am J Respir Crit Care Med 2017;195(11):1477-1485.

16. Cabello B, Thille AW, Roche-Campo F, Brochard L, Gómez FJ, Mancebo J. Physiological comparison of three spontaneous breathing trials in difficult-to-wean patients. Intensive Care Med 2010;36(7):1171-1179.

This article is approved for Continuing Respiratory Care Education credit. For information and to obtain your CRCE

(free to AARC members) visit

www.rcjournal.com

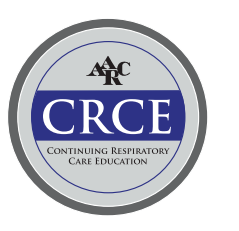

